\title{
Industry and leadership experiences of the heads of departments and their impact on the performance of public universities
}

\author{
Robert Rybnicek \\ Department of Corporate Leadership and Entrepreneurship, \\ Karl-Franzens-Universität, Graz, Austria \\ Karl-Heinz Leitner \\ Department of Corporate Leadership and Entrepreneurship, \\ Karl-Franzens-Universität, Graz, Austria and \\ Innovation System Department, \\ AIT Austrian Institute of Technology GmbH, Vienna, Austria, and \\ Lisa Baumgartner and Julia Plakolm \\ Department of Corporate Leadership and Entrepreneurship, \\ Karl-Franzens-Universität, Graz, Austria
}

Industry and leadership experiences

Received 30 October 2018 Revised 11 April 2019 Accepted 12 April 2019

\begin{abstract}
Purpose - The purpose of this paper is to identify whether the prior industry experience (IE) or industry leadership experience (ILE) of the head might influence the department's publication output, the ability to acquire external research funds or its entrepreneurial activities (e.g. the commercialization of research results through patents).

Design/methodology/approach - The study is based on data from 208 Austrian university departments and combines data from different sources (CVs of the heads of departments, commercial register, funding data and publication data).

Findings - The results show a positive relationship between ILE and the patent output of the departments as one indicator for the commercialization of research activities. Low positive effects of IE on the extent of third-party funding were also found. Furthermore, the scientific experience of the head of department has a positive influence on the publication output of the whole department.

Practical implications - The findings suggest that the scientific ability of researchers should be key when selecting the head of a department, due to the fact that scientific performance is still essential for most of these units. However, when universities seek to focus more strongly on other, for example, entrepreneurial activities, then additional competencies come into play. As the actual focus of universities is currently subject to change, former IE and ILE will become increasingly more important and the heads of departments will play a decisive role in the transition toward becoming an entrepreneurial university. Therefore, universities are well advised to integrate these experiences in the job specifications and to establish processes that facilitate the change from an industrial to a university job or which allow "double lives" in university and industry. Originality/value - Previous studies have mostly investigated the role of the scientific experience of academic leaders in the research performance of their institution in later decades. This study examines the
\end{abstract}

(C) Robert Rybnicek, Karl-Heinz Leitner, Lisa Baumgartner and Julia Plakolm. Published by Emerald Publishing Limited. This article is published under the Creative Commons Attribution (CC BY 4.0) licence. Anyone may reproduce, distribute, translate and create derivative works of this article (for both commercial \& non-commercial purposes), subject to full attribution to the original publication and authors. The full terms of this licence may be seen at http://creativecommons.org/ licences/by/4.0/legalcode

We would like to express our gratitude to the Statistics Austria for their support in the analysis of data.

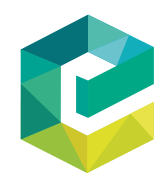

Management Decision

Vol. 57 No. 12, 2019 pp. $3321-3345$ Emerald Publishing Limited
$0025-1747$ DOI 10.1108/MD-10-2018-1173 
$\mathrm{MD}$

57,12

actual relevance of previous entrepreneurial experiences of heads of departments to the departments' research performance, the ability to acquire external research funds or their entrepreneurial activities.

Keywords Collaboration, Entrepreneurial university, Leadership experience, Industry experience, Third-party funds

Paper type Research paper

\section{Introduction}

In recent decades, a number of concepts and strategies, such as the entrepreneurial university (Etzkowitz, 2003), new public management (Leisytë and Kizniene, 2006), the third mission of universities (Zomer and Benneworth, 2011; Pinheiro et al., 2015), the Triple-Helix (Etzkowitz and Leydesdorff, 2000) and the Mode 2 of knowledge production (Gibbons et al., 2002) have been proposed to progressively transform universities into entrepreneurial institutions. These universities are closely linked to the demands of industry, society and governments (Etzkowitz, 2016), they are often required to diversify their funding streams (Tijssen, 2006; Slaughter and Leslie, 2001), and they are characterized by the implementation of management tools primarily known from the private sector (Peus et al., 2015). As a consequence, the role of scientists has changed from truth-seeking academics to entrepreneurial actors capable of considering the practical implications of their research and matching their knowledge with innovation (Elia et al., 2017; Etzkowitz and Viale, 2010). Today, polyvalent scientists are required with "double lives" in universities, industry and/or government (Etzkowitz and Viale, 2010).

This study aims to take a closer look at the "double lives" of scientists and their impact on entrepreneurial and research activities. To be more specific, with our research, we seek to identify whether prior industry experience (IE) or industry leadership experience (ILE) of the heads of departments might influence the department's entrepreneurial activities (e.g. the commercialization of research results through patents), its ability to acquire external research funds or its publication output. While previous studies have mainly investigated the role of the scientific experience of academic leaders in the research performance of their institution in later decades (Goodall, 2006, 2009; Goodall et al., 2014), research on other non-scientific experiences of academic leaders is still in its infancy. Therefore, our study concentrates on the research question:

$R Q 1$. Do the IE or ILE of heads of departments impact the departments' performance?

We address this research gap and contribute to the literature by delivering a more comprehensive model, explaining the entrepreneurial and research performance of university departments. By adding this "entrepreneurial" perspective, our research enhances the understanding of how entrepreneurial universities can improve their performance to meet the increasing demands made by industry, society and governments.

Our research methodology has been organized in several phases: First, we analyzed the literature on entrepreneurial universities and leadership of universities to understand the relationship between different scientific and non-scientific experiences and other key performance indicators. Then, we captured data from 208 Austrian university departments in the natural and technical sciences and combined data from different sources. We have collected data about the heads of departments from CVs and the commercial register, used funding data from the biannual survey by Statistics Austria and collected publication data from internal publication databases of the universities. Finally, we conducted ordinary least squares (OLS), logistic and negative binomial regression analyses to test our hypotheses and to determine the importance of our variables.

The results show a positive relationship between ILE and the patent output of the departments as one indicator for the commercialization of research activities. Low positive effects of IE on the extent of third-party funding were also found. Furthermore, the 
publication output of the head of department has a positive influence on the publication output of the whole department.

Our findings have important policy implications and suggest that the scientific ability of researchers should be key when selecting the head of a department, due to the fact that scientific performance is still essential for most of these units. However, when universities seek to focus more strongly on other, for example, entrepreneurial activities, then additional competencies come into play. As the actual focus of universities is currently subject to change, we assume that former IE and/or ILE will become increasingly more important and the heads of departments will play a decisive role in the transition toward becoming an entrepreneurial university. Therefore, universities are well advised to integrate these experiences in the job specifications of heads, professors or scientists in general and to establish processes that facilitate the change from an industrial to a university job or which allow "double lives" in university and industry.

In the next section, we review the relevant literature and propose testable hypotheses. The method and data used are described in Section 3 and the results are presented in Section 4. In Section 5, we discuss our results in the context of the literature, and the implications for academia and practice are highlighted in Section 6.

\section{Theoretical background and hypotheses development}

The entrepreneurial university and related concepts have induced multiple transformations at universities in recent years. Changing governance structures, greater autonomy, the need to diversify funding streams and the increasing request to transfer knowledge in collaboration with different partners will require new capabilities from academic leaders (Rybnicek, 2015). In this section, we discuss important aspects of entrepreneurial universities and academic leadership on a general level, before developing our hypotheses in detail.

\subsection{Entrepreneurial universities}

Today's universities play a central societal and economical role and the effort to adapt policies and practices to better translate knowledge into economic activities has increased worldwide (Etzkowitz, 2016). In contrast to traditional universities, which focused mainly on teaching (first mission) and/or research (second mission; for a concise overview of the evolution of universities since the first industrial revolution, see Elia et al., 2017), entrepreneurial universities and their members need to collaborate more strongly with industrial and governmental partners to mutually create new innovations and to foster the development of a region (Elia et al., 2017). In this sense, entrepreneurial universities can be described as those universities that deliver on their third mission (Jones et al., 2013). Therefore, the performance of universities is nowadays not only measured by indicators referring to the first two missions (such as the number of publications or the number of students), but also by indicators referring to the third mission (such as the number of patents or the share of third-party funding; Laredo, 2007) to better reflect the actual challenges.

As noted by Etzkowitz (2016), key elements of an entrepreneurial university include the endeavor to move research out of the university as protected intellectual property (IP), to organize firms within the university, and to integrate academic and business elements into new formats such as university-industry research centers. According to Tijssen (2006), entrepreneurial universities embrace an entrepreneurial and innovative spirit, promote an entrepreneurial culture, foster relationships with industry, transfer knowledge and technologies, and integrate managerial and market-related practices and tools. In other words, many universities will have to change fundamentally.

Regarding the transition from merely academic to entrepreneurial universities, Etzkowitz (2016) identifies three phases: in the initial phase, universities seek to develop their own 
$\mathrm{MD}$

57,12

3324

strategies, set their own priorities and raise their own resources. In the second phase, they actively commercialize their IP arising from their research activities. Finally, in the third phase, universities seek to play a decisive and strategic role in encouraging innovation in their region by improving the efficacy of its regional environment, often in the form of collaborations with external partners. However, universities choose very different strategies to become entrepreneurial institutions and to face present competitive challenges: for example, two important approaches are diversification and internationalization (Lombardi et al., 2019). Interestingly, as recently shown in an exploratory case study by Lombardi et al. (2019), a university's decision to opt for a particular strategy is also influenced by contingency factors, such as economic or historical reasons. Both strategies also have an impact on the type of transfer and commercialization activities universities focus on.

Within the university, several levels exist on which entrepreneurial patterns occur. These levels either concern the university itself, the members of the university or the interaction with the environment of the university (Röpke, 1998). Many universities have taken various actions to raise awareness among students (Secundo et al., 2017; Packham et al., 2010) as well as staff members of the need for an entrepreneurial approach. These universities promote managerial and attributional changes toward the commercialization of research findings because the entrepreneurial orientation of universities relies largely on cultural determinants, such as the managerial culture at universities, the governance culture of the higher education sector or the overarching socio-economic culture of a country (Tijssen, 2006). Eventually, universities wanting to change into entrepreneurial institutions need scientists that accept an entrepreneurial culture and embrace change (van Vught, 1999). In this changing process, academic leaders play a crucial role, particularly when managing severe changes and merging the individual scientific autonomy with new organizational goals (Bergner, 2015). Therefore, the role of academic leaders will be separately discussed in the following section.

\subsection{Academic leaders}

Generally, leadership is seen as the ability to lead a group of people or an organization. It is necessary to translate goals and objectives into accomplishments (Simon, 1976 as cited in Rowley and Sherman, 2003). The vast number of leadership theories can be briefly grouped into three different approaches: trait theories, which focus on the impact of a leader's relatively stable personality traits (like the Big 5; Costa and McCrae, 1992; Judge et al., 2002); behavioral theories, which refer to different leadership styles like those in Bass and Avolio's (1994) full-range model of leadership; and situational theories, which emphasize the various situational aspects when leading, for example Vroom and Yetton's (1973) contingency model. Despite the existence of these different theoretical approaches, there is ample evidence that successful leadership results from the interplay of personality traits, behavior and situational aspects (Bergner, 2015; Rosenstiel, 2006).

In our study, we focus on the heads of departments. Leadership at universities is different from other institutions (Bergner, 2015). For example, faculty members often find themselves in leadership roles without even having sought them (Rowley and Sherman, 2003). Furthermore, they might see leadership tasks as a tedious duty that impedes their progress in research, simultaneously knowing that they soon have to return to a regular faculty position, which might hinder them in making proper decisions in their role as a leader (Rowley and Sherman, 2003).

Despite these differences, there are also certain similarities between leaders at universities and private companies. Academic leaders are likewise responsible for the arrangement and implementation of changes and they have to develop appropriate plans and visions, provide necessary resources, facilitate productivity and motivate staff members (Peus et al., 2015). Furthermore, they have to consider stakeholder issues and they need to take accurate decisions as well as merge organizational needs with those of their staff (Rowley and Sherman, 2003). 
In the light of the new challenges, tasks and strategies that come together with the entrepreneurial university, it is evident that a more entrepreneurial mindset and business-oriented culture is needed at universities. Therefore, different management tools, more commonly used in the private sector, have already been transferred to public universities (Peus et al., 2015; Rybnicek, 2015). Similar to the implementation of new management tools, it is also to be expected that the necessary leadership skills at universities will converge with those observed in the private sector. Thus, scientists in leading positions will have to take over similar roles and duties as those leading in the private sector (Peus et al., 2015; Rowley and Sherman, 2003). Unfortunately, as reported by Gosling et al. (2009), heads of departments feel evident tensions between their roles ("social identities") as academics and as leaders. Hence, the question remains as to whether there are leaders of university departments that link these two roles in a beneficial way. With regard to this question, it is likely that those leaders who are experienced in being a leader in industry also have a certain advantage when it comes to holding a leadership position in an entrepreneurial university. This might be particularly true as scientific capabilities will increasingly merge with business-oriented and market-driven forces (Tijssen, 2006) and universities require leaders who can establish a culture of mutual understanding, respect, and trust to properly deal with the changes caused by the reorientation of universities (Sporn, 2001).

\subsection{Hypotheses}

Assuming that today's universities are becoming more entrepreneurial, we believe that new characteristics are becoming increasingly important in successfully leading a department. Subsequently, we develop our hypotheses in detail, which mainly concentrate on the impact of the IE and ILE of heads of departments.

Previous research suggests that leaders of expert organizations must themselves be acknowledged experts to be accepted by their subordinates (Mintzberg, 1980; Rybnicek et al., 2016). Thus, it can be clearly argued that leaders of research universities, faculties or departments need a high reputation as a scientist. Academic leaders have to define the research agenda in collaboration with their faculty, support the junior staff and help to promote the department within the scientific community. A high scientific reputation also ensures acceptance within the faculty of the university and departments. Goodall (2006) claims that world-class scholars, not administrators, make the best leaders of research universities. In several studies, Goodall identifies a relationship between the research productivity of academic leaders and the research performance of their institution in later decades (Goodall, 2006, 2009; Goodall et al., 2014). Based on a study of universities in the UK, she found that, on average, the research quality of a university (measured by the result of the research assessment exercise) improved some years after appointing a president who is an accomplished scholar (Goodall, 2009). In another study of 58 US universities over a 15-year period, Goodall et al. (2014) found that incoming heads of departments, whose publications were highly cited, generated a positive development in the departmental research productivity.

Based on these arguments we propose the following hypothesis:

H1. The publication output of the head of department is positively associated with the publication output at department level.

In the context of changing funding patterns, heads of departments have to increasingly acquire research funds from various sources. In the literature, it is argued that IE and ILE are of importance for budgeting and the acquisition of external research funds. Scholars studying entrepreneurial universities, for instance, stress the role of leadership capabilities and inter-sectoral mobility in the success of acquiring third-party funds and managing research departments.

Regarding ILE, scholars recently delivered empirical evidence of the effect of leadership capabilities and management practices on the performance of universities. 
$\mathrm{MD}$

57,12

3326

McCormack et al. (2014), for instance, investigated 248 heads of departments in UK universities, revealing a direct link between management practices and performance in research and teaching. Teodorescu (2000) examined the role of individual achievements (such as those who held other academic jobs and non-academic jobs) in publication productivity by studying faculty members in ten different countries worldwide. However, he reports a weak positive influence of holders of other academic jobs only in a Korean subsample.

Regarding IE, previous studies reported that inter-sectoral mobility can facilitate the building of competencies and relationships that are important for the acquisition of research projects. Concretely, IE expands the social capital, which again helps to develop and acquire research grants in collaboration with various partners. The network of the head of department represents an important resource the entire department can benefit from (Harvey et al., 2002). In addition, IE helps to build up trust in collaboration with non-academic partners and to establish a cooperative culture. Social capital of the head of department developed in previous jobs also facilitates the emergence of a common language and a better understanding of collaborative research work (Rouse et al., 1992). Furthermore, the experiences gained in non-academic jobs help heads of departments to cope with the growing complexity and interdisciplinarity of research problems (Verbree et al., 2011).

Based on these arguments we state:

H2a. IE of heads of departments has a positive impact on the level of third-party funding.

$H 2 b$. ILE of heads of departments has a positive impact on the level of third-party funding.

A number of authors claim that successful research universities are able to integrate excellent research that is also relevant to industry or can be commercialized (e.g. Godin and Gingras, 2000; van Looy et al., 2004). Ziman (1995) and Etzkowitz (2003) argue in this context that research groups ought to behave like "firms": they offer research results on a "market" in which the "customers" are funding agencies or private firms that buy results and offer funding. Today, both the publication output as well as the capability to acquire research funds are crucial for the success of research departments, and indeed, apart from refereed publications, the acquisition of research grants is often considered a success criterion by researchers too (Massy and Wilger, 1995). Hence, university departments need to be managed in such a way as to allow excellent research on the one hand and to promote the acquisition of external funds on the other. Therefore, we assume that the scientific output of the heads of departments as well as their IE and ILE jointly contribute to the ability to acquire external research funds.

We thus adopt an integrative approach and propose:

H3a. The publication output of the heads of departments positively moderates the relationship between $\mathrm{IE}$ and the level of third-party funding.

H3b. The publication output of the heads of departments positively moderates the relationship between ILE and the level of third-party funding.

The nature of research outcomes is influenced by the funding structure of the university. There is a broad literature about the effect of competitively acquired research grants on research performed at the university, department and individual level (e.g. Gulbrandsen and Smeby, 2005; Hottenrott and Thorwarth, 2011). Gulbrandsen and Smeby (2005) found in their study of Norwegian professors that academics who have strong relationships with industry have a higher publication output and also generate more patents. The average number of publications is lowest in the group of academics who have not acquired third-party funds. However, Gulbrandsen and Smeby (2005) also reveal that only a small group of researchers is able to publish extensively and to apply for grants. Departments who have high levels of external funds from industry are more likely to apply for patents, to conduct consultancy projects and to create spin-off companies. Altogether, they see no 
evidence that industrial projects reduce research performance due to secrecy requirements, shortage of time or incompatibility between the academic and industry culture.

Nevertheless, the acquisition of too much competitive funding may have a negative impact on research performance. For example, Conraths and Smidt (2005) point out that the dependency on competitive funding may result in quality decline and eventually put the institution at risk due to volatile income streams and insufficient cost coverage. A major handicap can also be seen in the negative impact of competitive funding on research careers (Polster, 2007). Conraths and Smidt (2005) also highlight the risk of the enormous efforts associated with the acquisition process of competitive research grants possibly restricting the career opportunities of junior scientists in particular.

A number of studies have delivered further evidence for an inverse u-shaped relationship between the amount of third-party funding and research performance. Bonaccorsi et al. (2006) analyze the impact of private funding on efficiency and find an inverse u-shape for Italian universities. In a similar vein, Schmoch and Schubert (2009) present evidence of an inverted u-shaped relationship between external funds and the total number of academic publications in a research group. More recently, Banal-Estañol et al. (2015) show that little engagement in industry-funded research has a positive impact on research output, while too many external funds show negative effects and indicate a non-linear effect.

Based on these arguments we propose:

H4. There is an inverse u-curved relationship between third-party funding and publication output at the department level.

Apart from traditional forms of technology transfer by means of collaborative research projects and contract research, the commercialization of research results has become increasingly important in many countries in recent years. With the implementation of the Bayh-Dole Act in 1980, US universities are allowed to file patents on inventions they elect to own for almost four decades. In the 1990s a number of European countries started to establish Bayh-Dole-type regulation to foster academic patenting, aiming to enhance the utilization of industry-relevant scientific research, contribute to economic development and job creation and to improve resource generation (Weckowska et al., 2018). Promoting the commercialization of research by the university through patenting and the generation of spin-off companies is a key pillar of the entrepreneurial university but has also been considered in the context of fostering the "third mission" activities of universities (e.g. Zomer and Benneworth, 2011; Pinheiro et al., 2015).

In Austria, the University Act 2002 changed the legal framework and allowed universities on the institutional level to claim the IP of their inventions. Prior to that, it was solely the professor's privilege to apply for patents, although this rarely occurred. In recent years, as in many other European countries (Pinheiro et al., 2015), a number of specific promotion programmes and initiatives with targeted funding schemes have been established, supporting universities in their commercialization activities. Austrian universities established Technology Transfer Offices, created IP policies and established long-term plans and goals to become more entrepreneurial (BMWFW, 2016).

We claim that IE and ILE both have a positive impact on the likelihood of generating patents as both types of occupational engagement facilitate or enable the identification of business and market opportunities. This can be argued based on the diversity hypothesis (Dietz and Bozeman, 2005), reasoning that more diversity in work experience allows researchers to develop stronger network ties, skills and access to enhanced knowledge gatekeepers, which, in turn, enables the commercialization of innovative research outputs. In one of the few studies analyzing the role of the career experience of scientists, Dietz and Bozeman (2005) found that IE measured in years had a positive impact on the patent rate.

In a related vein, recent results suggest that third-party funding is also correlated with the generation of patents (Gulbrandsen and Smeby, 2005). Interestingly, Hottenrott and 
$\mathrm{MD}$

57,12

3328

Thorwarth (2011) found that while a higher share of industry funding has no effect on the number of patents generated by professors, it has a positive impact on citations per patent. The authors see this as a quality indicator as only granted patents can receive citations.

Based on these arguments we propose the following hypotheses:

H5a. IE of the heads of departments is positively associated with the patent output.

$H 5 b$. ILE of the heads of departments is positively associated with the patent output.

$H 5 c$. There is a positive relationship between third-party funding and the patent output.

Our conceptual model, which comprises the above-discussed hypotheses, is depicted in Figure 1.

\section{Methods and data}

In this section, we provide information regarding the research method, the sample, the data collection and the data analysis. Further information is provided in the Appendices.

\subsection{Research method}

Our research methodology was organized in several phases. First, we analyzed the literature on entrepreneurial universities and leadership of universities in order to understand the relationship between different scientific and non-scientific experiences of heads of departments and other key performance indicators. Then, we captured our data from the national statistical office, the reporting systems of the universities, the CVs of the heads of departments, and the national commercial register to acquire meaningful data. The research method adopted to test our hypotheses was a quantitative empirical study. Considering the different types of variables, we conducted OLS, logistic and negative binomial regression analyses. Regression analyses allow, for example, the examination of the relationship between one dependent variable and several independent variables, to determine the importance of the independent variables, to investigate contingencies among the independent variables or to compare sets of independence variables (Tabachnick and Fidell, 2014).

\subsection{Sample}

The study is based on a sample of 208 university departments in natural and technical sciences from ten public Austrian universities[1]. We thus covered all public universities apart from medical universities and arts universities. We focused on natural and technical

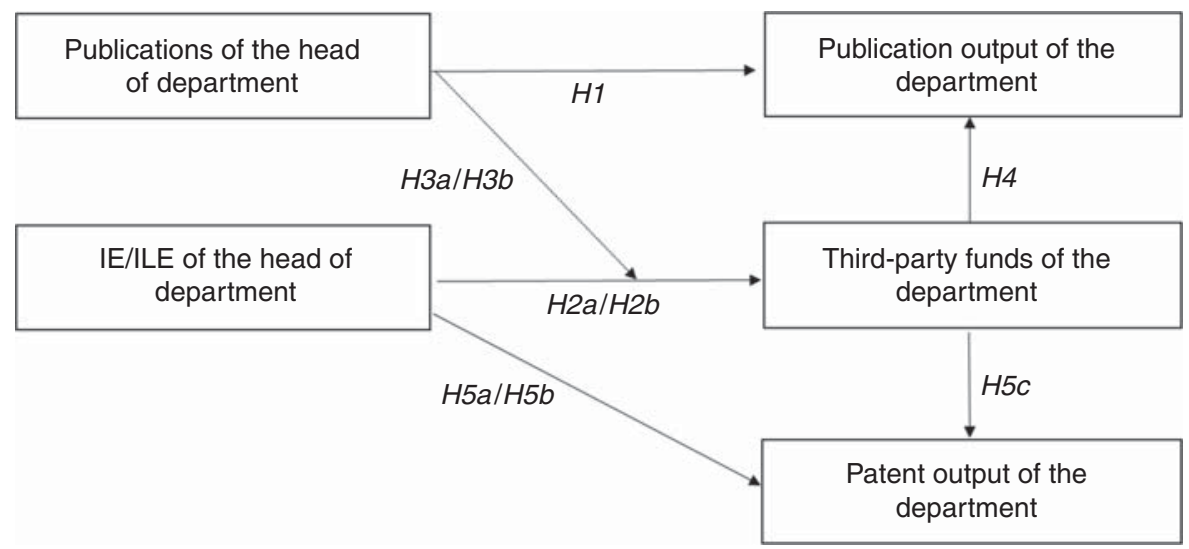

Figure 1.

Conceptual model 
sciences as in both disciplines external funding has grown considerably in the last two decades and plays a crucial role (BMWFW, 2014). Therefore, we assume that in these disciplines academic research is relevant to industry and, vice versa, IE is relevant to the university departments and their heads. Considering the organizational and governance structure of Austrian universities, departments can be considered as relevant units of observation. These departments have a large autonomy, are requested to strategically steer development and typically have 20 to 40 employees. The faculties or schools of the universities are usually too big and heterogeneous to compare them and to analyze the impact of various input variables on the output.

We considered the development of the departments over a period of three years between 2013 and 2015 and selected those departments that had the same head of department over this period of time, which was the case for 77 percent of a total of 270 natural and technical sciences departments from the ten universities. As the turnover is rather small, we did not take into account those departments that changed their heads. In Austria, the recruitment of the heads of departments is the responsibility of the universities. There exist no laws or governmental rules about the required qualifications of heads, so the universities can determine their own rules. However, today many universities consider leadership or managerial experience in the appointment of professors (e.g. Vienna University of Technology, University of Graz), following the trend to integrate these qualifications and experiences already in the job specifications of a professorship (Rybnicek et al., 2016).

\subsection{Data collection}

We collected data from various sources to determine our dependent and independent variables. The measurements for IE and ILE are not overlapping and capture different aspects, qualities and qualifications of the $\mathrm{CVs}$ and the commercial register: to determine IE, we mainly analyzed the CVs from the heads of departments. We sought CVs on the department webpages but also on additional internet sites in order to ensure up-to-date CVs. For the analyses, we developed a coding system to collect data regarding IE (excluding positions at universities, non-governmental organizations and public institutions). Additionally, we included board responsibilities from the Austrian commercial register. For ILE we analyzed the Austrian commercial register and focused here on the functions "managing director," "owner of the company" and "authorized representatives" of the company. In this context, we analyzed the type and duration of position. ILE is measured in months (reporting day was July 31, 2017), while IE is a binary variable as it was not possible to extract the number of years from all CVs. However, for the subgroup, for which we were able to collect the exact number of years, we ran all relevant statistical tests. These tests delivered no evidence for different results or a specific effect of the length of IE. In addition, we identified the age of the heads of departments, which served as control variable.

In order to determine the publication output of the departments we used the reporting system for Austrian universities, which is defined by law, and collected data from the public research portals of the universities. We constructed a publication measure encompassing articles in journals, monographs, edited books and proceedings and used full counting. In addition, the number of patents is disclosed by the reporting system. We collected the number of total publications for all members of the departments for the years 2013 to 2015 and calculated the mean.

In addition, we collected separately the number of publications of the heads of departments and calculated a dichotomous variable with those heads that belong to the top 25 percent in terms of the publication output, investigating the impact of the top performers. We thereby aimed to control for the fact that the publications of the heads of departments are also included in the research output of the departments with the intention of being able to disentangle both effects. We normalized the number of publications taking into account the discipline. 
$\mathrm{MD}$

57,12

3330

Data about R\&D expenditures are collected by Statistics Austria, which biannually conducts an obligatory survey about the public and private third-party funding sources among the university departments. We used the amount of third-party funding as a percentage of the total funding. In addition, we distinguished between public and private third-party funds as the percentage of total funding. Total funding of the departments consists of the block grants from the Federal Ministry and all other third-party funds. Thirdparty public funding includes funding from national and international public science and research promotion funds, with the Austrian Science Fund (FWF) and Research Promotion Agency (FFG) being the most important sources in Austria. Funds from the European Commission and the Framework Programmes are also included. Third-party private funds cover funds from private organizations, with enterprises as the most important source. We also calculated the squared value to test possible non-linear effects of funding on the publication output (Bolli and Somogyi, 2011).

In addition, Statistics Austria collects data about R\&D personnel, which is used to determine the number of researches, measured as full-time equivalent, at department level. We used the data for the survey in 2013 and 2015 and calculated the mean for the three-year period.

\subsection{Data analysis}

Considering the different types of variables, we conducted OLS, logistic and negative binomial regression analyses. We log-transformed the publication output variable in order to meet the requirements to run an OLS regression and analyzed residuals, error terms and outliers to check for heteroscedasticity and normality of the residuals. When using total third-party funding as dependent variable, normality tests and controls of error terms delivered no concerns that test requirements were not met. However, the private third-party funds did not meet the assumption of normality to conduct an OLS regression and we hence used a binary variable, distinguishing between the top 25 percent and employing a logistic regression. In addition, the number of patents, which serves as dependent variable in one hypothesis test, had a highly skewed count data and revealed over-dispersion. We thus ran a negative binomial regression model for studying the patent output. The variables location (Vienna), discipline (technical sciences), type of university (technical university), publication performance of the head of department (top group) and IE were binary variables coded with 0 (without the defining characteristic) and 1 (with the characteristic). When integrating these dichotomous independent variables in the logistic regression and negative binomial regression models, the first category coded as 0 served as reference group. The list of the used variables and their description can be found in Appendix 1.

We controlled for size, discipline and age, which should have an impact on the output, according to the literature (Carayol and Matt, 2006). For the variable size and age, we also calculated the squared value in order to control for any possible non-linear effects (Bolli and Somogyi, 2011). In addition, we used the location of the university (= Vienna) as control, took into account the discipline (natural science vs technical sciences) and checked whether the departments belong to a technical university. In order to differentiate between the disciplines, we used the "Austrian Systematics of the Sciences" (Statistics Austria, 2013). Natural sciences cover six subfields (e.g. mathematics, physics, biology) and technical sciences cover eleven subfields (e.g. construction, mechanical engineering, electrical engineering).

\section{Results}

Descriptive statistics for the variables used in the study, including means, standard deviation and correlation, are provided in Appendix 2. With regard to our main variables of interest, IE and ILE, the data show that among the 208 heads of departments, 83 had prior IE and 50 had ILE lasting, on average, 60 months. In total, 54 heads of departments belong 
to the top 25 percent group in relation to their publication output. Overall, 100 departments are engaged in natural sciences and 108 departments belong to technical sciences and engineering. A total of 125 departments belong to one of the three technical universities and 77 departments are part of the three universities in Vienna.

\subsection{Publication performance}

For the analysis of $H 1$, we conducted a regression analysis with the publication output as dependent variable and the publication output of the heads of departments as the main independent variable. The publication output of the heads of departments is a binary variable distinguishing between individuals who belong to the top 25 percent group in terms of their publication output or those who are below this threshold. In addition, we used size, discipline, university type and age as controls. We also incorporated size and age as squared terms in order to check for possible non-linear effects.

The results show that the publication output of the head of department has a positive impact (Table I, Model $1, b=0.199$ ) on the output of the department, providing support for $H 1$. The regression model delivers further evidence that the size of the department, the discipline and the type of university have a signification impact on publication output. As can be expected, the size of the department measured by the number of research staff has the strongest effect (Table I, Model $1, b=1.290$ ) on the publication output, also showing a non-linear effect as the squared term has negative value (Table I, Model $1, b=-0.765$ ). Technical sciences and engineering departments and departments in technical universities have, on average, a lower publication output compared to other departments. The error terms in the multiple regressions were also checked for outliers and heteroscedasticity and raised no concerns.

Although we have not proposed a specific hypothesis, we also tested in a further model the impact of IE and ILE (Table I, Model 2). This model revealed no effects for either variable.

\subsection{IE and ILE and the impact on third-party funding}

To test $H 2 a$ and $H 2 b$ dealing with the effect of IE and ILE, we conducted a regression model with the share of total third-party funds (Table II). We first analyzed the effect of IE (Table II, Model 1) and then investigated the role of ILE (Table II, Model 3), including different controls. For all models we checked outliers and heteroscedasticity, which raised no concerns of them violating any assumptions. Model 1 revealed a low positive coefficient for IE. ILE revealed no effect (Table II, Model 3). However, size, discipline and the location of the department had an effect on the amount of acquired third-party funds. Larger departments and departments in

\begin{tabular}{|c|c|c|c|}
\hline Independent & Model 1 & Model 2 & \\
\hline Publication output of the head of department (top) & $0.199 * * *$ & $0.198 * * *$ & \\
\hline Size & $1.290 * * *$ & $1.303^{* * *}$ & \\
\hline $\mathrm{Size}^{2}$ & $-0.765^{* * *}$ & $-0.763^{* * *}$ & \\
\hline Technical sciences & $-0.207 * * *$ & $-0.205^{* * *}$ & \\
\hline Technical university & $-0.178 * * *$ & $-0.169 * * *$ & \\
\hline Vienna & 0.054 & 0.057 & \\
\hline Age & 0.643 & 0.651 & \\
\hline $\mathrm{Age}^{2}$ & -0.578 & -0.575 & \\
\hline IE & & 0.046 & \\
\hline ILE & & -0.073 & $\begin{array}{l}\text { Table I. } \\
\text { Dependent variable: }\end{array}$ \\
\hline$n$ & 206 & 206 & Dependent variable: \\
\hline$F$-value & $54.297 * * *$ & $43.890^{* * * *}$ & publication output \\
\hline Adj. $R^{2}$ & 0.675 & 0.677 & $\begin{array}{l}\text { of the department } \\
2013-2015(\log )\end{array}$ \\
\hline Note: $* * * p<0.001$ & & & (standardized $\beta$ ) \\
\hline
\end{tabular}

Industry and leadership experiences

3331

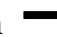


$\mathrm{MD}$

57,12

Dependent variable:

third-party funds total

(in \%) of the

department

2013-2015

(standardized $\beta$ )

\begin{tabular}{lcccc}
\hline Independent & Model 1 & Model 2 & Model 3 & Model 4 \\
\hline IE of the head of department & $0.167^{* *}$ & $0.175^{* * *}$ & & \\
ILE of the head of department & & & 0.029 & 0.030 \\
Size & $0.329^{* * *}$ & $0.328^{* * * *}$ & $0.322^{* * *}$ & $0.322^{* * *}$ \\
Technical sciences & $0.210^{* * *}$ & $0.204^{* *}$ & $0.243^{* * *}$ & $0.244^{* * *}$ \\
Vienna & $-0.189^{* * *}$ & $-0.186^{* * *}$ & $-0.212^{* * *}$ & $-0.210^{* * *}$ \\
Technical university & -0.101 & -0.101 & -0.119 & -0.121 \\
Age & 0.597 & 0.579 & 0.637 & 0.632 \\
Age & -0.601 & -0.581 & -0.656 & -0.653 \\
Publication output of the head of department (top) & -0.007 & -0.026 & 0.026 & 0.042 \\
IE $\times$ Publication output of the head of department & & -0.031 & & -0.026 \\
ILE $\times$ Publication output of the head of department & & & & 207 \\
$n$ & 207 & 207 & 207 & 207 \\
$F$-value & $6.060^{* * *}$ & $5.374^{* * * *}$ & $5.9674 * * *$ & $4.628^{* * * *}$ \\
Adj. $R^{2}$ & 0.164 & 0.160 & 0.140 & 0.136 \\
Notes: ** $p<0.01 ; * * * p<0.001$ & & & & \\
& & & &
\end{tabular}

technical sciences and engineering have a higher likelihood of acquiring third-party funds. Universities in Vienna have lower levels of third-party funds, which are partly explained by a lower share of private third-party funding and fewer industrial companies. The age of the head of department showed no significant impact. In both models we also included the publication output of the heads of departments, which revealed no influence either. Thus, we found support for $H 2 a$, but have to reject $H 2 b$.

In addition, we tested the effect of IE and ILE on the amount of third-party funding from private sources by separate models. As the private third-party funding variable was skewed and did not meet the requirements to run an OLS regression, we conducted a logistic regression, splitting the departments into two groups. We compared the departments that had private third-party funding of more than 20 percent of total funding with the reference group that received below 20 percent. We were particularly interested in explaining the determinant for the success of the top performing departments and thus cut at 20 percent. Table III (Models 1 and 2) depicts the results of this analysis. We found a positive coefficient

Table III.

Dependent variable: private third-party funds of the department 2013-2015 (> 20\%), logistic regression (coefficient B)

\begin{tabular}{|c|c|c|c|c|}
\hline Independent & Model 1 & Model 2 & Model 3 & Model 4 \\
\hline Constant & -5.146 & -3.863 & -4.486 & -19.150 \\
\hline $\mathrm{IE}$ of the head of department & 0.407 & & 0.529 & \\
\hline ILE of the head of department & & 0.003 & & 0.004 \\
\hline Size & 0.009 & 0.013 & 0.011 & 0.010 \\
\hline Technical sciences & $3.372 * *$ & $3.559 * *$ & $3.453^{* *}$ & $3.700^{* *}$ \\
\hline Vienna & -19.107 & -19.234 & -19.152 & -19.201 \\
\hline Technical university & -0.454 & -0.584 & -0.503 & -0.716 \\
\hline Age & -0.551 & -0.610 & -0.588 & -0.689 \\
\hline $\mathrm{Age}^{2}$ & 0.005 & 0.005 & 0.005 & 0.006 \\
\hline Publications of the head of department (top 25\%) & -0.273 & -0.212 & 0.307 & 0.628 \\
\hline $\mathrm{IE} \times$ Publications of the head of department & & & -0.876 & \\
\hline ILE $\times$ Publications of the head of department & & & 208 & $\begin{array}{c}-0.040 \\
208\end{array}$ \\
\hline $\begin{array}{l}n \\
\chi^{2}\end{array}$ & $40.049^{* * * *}$ & $39.953 * * *$ & $40.351 * * *$ & $42.001^{* * * *}$ \\
\hline Log likelihood & 82.444 & 82.541 & 82.142 & 80.492 \\
\hline Cox and Snell $R^{2}$ & 0.175 & 0.175 & 0.176 & 0.183 \\
\hline Notes: $* * p<0.01 ; * * * p<0.001$ & & & & \\
\hline
\end{tabular}


for the effect of IE on private third-party funding, although it was not significant. We found no evidence for an effect of ILE on acquiring private third-party funds. The discipline again explains the level of private third-party funding, showing that technical sciences and engineering departments have higher levels thereof. In contrast, size, age of the head of department and type of university had no significant effect. The variable location (Vienna) reveals a strong magnitude but the term was not significant.

We further analyzed the data by conducting a nominal regression model with three categories (Group 1: above 20 percent; Group 2: between 0and 20 percent; Group 3: 0 percent) of the independent variable private third-party funding. This model revealed that IE has a positive significant effect on the extent of private third-party funding when comparing those departments that have no private funds at all with the top private-funding group (not shown here). Thus, among the group of departments that have not acquired any private external funds, heads of departments are more likely to not have any IE either. However, an analysis showed no effect of ILE on private third-party funding.

\subsection{Joint interaction of publication performance, IE and ILE and the impact on third-party funding}

We were further interested in a joint effect of the publication output of the heads of departments and their respective IE and ILE (H3a and H3b). Models 2 and 4 (Table II) portray the regression results by adding an interaction term. However, neither model showed significant effects, with very small coefficients for the interaction term, and thus we can conclude that the publication output does not moderate any possible effect of IE and ILE on the likelihood of successfully acquiring third-party funds. Therefore, $H 3 a$ and $H 3 b$ have to be rejected.

With regard to private third-party funding, we also tested for a possible interaction effect between publication output and IE and ILE (Table III, Models 3 and 4) showing no significant results.

\subsection{Inverse u-curved relationship between third-party funding and publication performance}

$H 4$ suggests that there is an inverse u-curved relationship between third-party funding and publication output of the department. We conducted a number of models by investigating the role of the total share of third-party funding on the publication output, but also studied separately the role of private and public third-party funds. We entered quadratic terms to test possible non-linear relationships. Table IV (Models 1-4) shows the results of the corresponding regression models. We found clear evidence for an inverted ushaped effect of third-party funding on the publication output for the total (Table IV, Model 2, $b=0.504$ ) and public share (Model $4, b=0.356$ ) of third-party funds. The squared terms had significant negative signs revealing the non-linear effect. However, this pattern did not hold for the private third-party funds (Table IV, Model 4). The publication output of the heads of departments again had a significant impact on the total publication output of the departments. We also included IE and ILE in these models, which showed no effect on the publication output (Table IV, Models 3 and 4). There was no interaction effect between publication output of the head of department and managerial experience either (not shown here).

\subsection{IE, ILE and third-party funds and the impact on patent output}

Finally, we investigated potential predictors of a department's patent output (H5a-H5c). Due to the nature of the dependent variable number of patents, which was skewed, we ran a negative binomial regression model. Table $\mathrm{V}$ depicts the results with the main effect variables and control factors. ILE was entered as a binary variable in this model. 
$\mathrm{MD}$

57,12

\section{4}

\section{Independent}

Publication output of the head of department (top)

Size

Size squared

Technical sciences

Technical university

Vienna

Age

$\mathrm{Age}^{2}$

Third-party funds total

Third-party funds squared

Third-party funds public

Third-party funds public squared

Third-party funds private

Third-party funds private squared

Table IV.

Dependent variable: publication output of the department 2013-2015 (log) (standardized $\beta$ )
IE

ILE

$n$

$F$-value

Adj. $R^{2}$

Notes: $* p<0.05 ; * * p<0.01 ; * * * p<0.001 ; * * * * p<0.10$

\begin{tabular}{cccc} 
Model 1 & Model 2 & Model 3 & Model 4 \\
\hline & $0.196^{* * * *}$ & $0.186^{* * * *}$ & $0.177^{* * * *}$ \\
$1.407^{* * *}$ & $1.257^{* * * *}$ & $1.276^{* * * *}$ & $1.239^{* * * *}$ \\
$-0.855^{* * *}$ & $-0.735^{* * * *}$ & $-0.738^{* * * *}$ & $-0.711^{* * * *}$ \\
$-0.180^{* * *}$ & $-0.186^{* * *}$ & $-0.181^{* * *}$ & $-0.167^{* * *}$ \\
$-0.200^{* * *}$ & $0.198^{* * *}$ & $-0.199^{* * * *}$ & $-0.173^{* * * *}$ \\
0.052 & 0.039 & 0.039 & 0.033 \\
$0.821^{* *}$ & $0.703^{* * *}$ & $0.714^{*}$ & 0.630 \\
$-0.785^{* *}$ & $-0.650^{* * *}$ & $-0.651^{*}$ & -0.567 \\
$0.508^{* *}$ & $0.504^{* * *}$ & $0.497^{* * *}$ & \\
$-0.557^{* * *}$ & $-0.546^{* * *}$ & $-0.544^{* *}$ & \\
& & & $0.356^{* *}$ \\
& & & $-0.367^{* *}$ \\
& & & 0.023 \\
& & 0.039 & -0.124 \\
206 & & $-0.074^{* * * * *}$ & -0.048 \\
$45.050^{* * *}$ & $47.2066^{* * * *}$ & 206 & 206 \\
0.674 & 0.708 & 0.694 & $33.673^{* * * *}$ \\
& & & 0.691
\end{tabular}

\begin{tabular}{lcc}
\hline Independent & $B$ & Exp(B) \\
\hline Constant & $-15.602^{* * *}$ & \\
Third-party funding public & -0.003 & 0.997 \\
Third-party funding private & 0.011 & 1.009 \\
Size & $0.049^{* * *}$ & 1.050 \\
Technical sciences & 0.215 & 0.807 \\
Technical university & $-0.971^{* *}$ & 2.640 \\
Vienna & -0.438 & 1.550 \\
Age & $-0.664^{*}$ & 1.904 \\
Age & $-0.006^{* *}$ & 0.994 \\
Publication output of the head of department (top) & $1.347^{* * * *}$ & 0.260 \\
IE & 0.205 & 0.815 \\
ILE & $0.778^{* *}$ & 0.459 \\
$n$ & 208 & \\
Likelihood ratio $\chi^{2}$ & $161.434^{* * *}$ & \\
Notes: $* p<0.05 ; * * p<0.01 ; * * * p<0.001$ & &
\end{tabular}

The regression analysis shows that both IE and ILE had positive coefficients, with ILE being significant on the 1 percent significant level. The ILE coefficient is 0.778 . Thus, heads of departments with ILE are more likely to publish patents, which provide support for our $H 5 b$. However, $H 5 a$ has to be rejected.

In addition to IE and ILE we also investigated the impact of third-party funding on the likelihood of generating patents. However, we found no support for the assertion that there is a positive relationship between third-party funding and the patent output. Neither private nor public third-party funds showed any significant impact. Therefore, $H 5 c$ has to be rejected.

The discipline and location of the university had no effect on the patent output either. However, we found that the age of the head of department had a negative significant effect and the size of the department a weak positive impact on the patent output. The publication 
output was positively correlated with the patent output of departments, revealing that the top-performing heads of departments are able to convert ideas that can be commercialized. Technical universities were less likely to generate patents, which might be explained by specific patent policies within some universities and a weaker position in negotiating arrangements on how to deal with IP rights in third-party-funded research projects. To check the robustness of the results we also conducted a logistic regression with a binary dependent variable (having patents or not), which delivered similar findings and confirmed our results.

\section{Discussion}

This section provides some considerations about the scientific (5.1) and entrepreneurial experiences (5.2) of heads of departments and some characteristics of departments (5.3) and their impact on research performance and entrepreneurial activities. Table VI summarizes the findings from the validation of our hypotheses. In line with recommendations of the American Psychological Association (2013), we reported all tested hypotheses in order to avoid selective reporting and thus to strengthen the explanatory power of the entire study.

\subsection{Scientific experience of the heads of departments}

We found evidence that the research performance of the head of department has a positive impact on the total research performance of his or her department. This result is in line with Goodall's findings, which also revealed a positive relationship between the research ability of presidents and heads and the future research performance of their institutions (Goodall, 2006, 2009; Goodall et al., 2014). Goodall et al. conclude in their research that better researchers may have a better inherent knowledge about academe and about the organization's core business, that they may have a better status, more credibility and greater respect within the scientific community, and that their appointment sets the academic standards and signals the institution's priorities. In this context, it is necessary to bear in mind that universities are expert organizations with highly qualified specialists - the scientific researchers - as employees. Leaders of such organizations must themselves be acknowledged experts to be accepted by those who work under them and to gain power to lead them (Mintzberg, 1980; Rybnicek et al., 2016). Hence, a good scientific performance of the heads of departments seems to be the necessary basis to successfully lead and manage a department.

\begin{tabular}{|c|c|c|c|c|}
\hline & Independent variable(s) & $\begin{array}{l}\text { Dependent } \\
\text { variable(s) }\end{array}$ & Results & Other results \\
\hline$H 1$ & Publications of the head & $\begin{array}{l}\text { Publication } \\
\text { output of the } \\
\text { department }\end{array}$ & Supported & $\begin{array}{l}\text { Size, university type and discipline have an } \\
\text { impact on publication output; IE and ILE } \\
\text { have no effect }\end{array}$ \\
\hline H2 & $\begin{array}{l}\text { a. IE of the head } \\
\text { b. ILE of the head }\end{array}$ & $\begin{array}{l}\text { Third-party } \\
\text { funds of the } \\
\text { department }\end{array}$ & $\begin{array}{l}\text { a. Supported } \\
\text { b. Rejected }\end{array}$ & $\begin{array}{l}\text { Size, location and discipline have an impact } \\
\text { on third-party funds }\end{array}$ \\
\hline H3 & $\begin{array}{l}\text { a. Publications of the } \\
\text { head } \times \text { IE of the head } \\
\text { b. Publications of the } \\
\text { head } \times \text { ILE of the head }\end{array}$ & $\begin{array}{l}\text { Third-party } \\
\text { funds of the } \\
\text { department }\end{array}$ & $\begin{array}{l}\text { a. Rejected } \\
\text { b. Rejected }\end{array}$ & $\begin{array}{l}\text { Size, university type and discipline have an } \\
\text { impact on third-party funds }\end{array}$ \\
\hline$H 4$ & $\begin{array}{l}\text { Third-party funds of } \\
\text { the department }\end{array}$ & $\begin{array}{l}\text { Publication } \\
\text { output of the } \\
\text { department }\end{array}$ & Supported & $\begin{array}{l}\text { Size, age, discipline and university type have } \\
\text { an impact on publication output }\end{array}$ \\
\hline H5 & $\begin{array}{l}\text { a. IE of the head } \\
\text { b. ILE of the head } \\
\text { c. Third-party funds } \\
\text { of the department }\end{array}$ & $\begin{array}{l}\text { Patent output of } \\
\text { the department }\end{array}$ & $\begin{array}{l}\text { a. Rejected } \\
\text { b. Supported } \\
\text { c. Rejected }\end{array}$ & $\begin{array}{l}\text { Size, university type, age and publication } \\
\text { have an impact on patent output }\end{array}$ \\
\hline
\end{tabular}

Industry and leadership experiences

3335

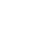


$\mathrm{MD}$

57,12

\subsection{Entrepreneurial experience of the heads of departments}

However, not every good scientist is a good leader (Goodall, 2009) and the scientific ability of leaders might only be a proxy for some other talent that is useful to leaders (Goodall, 2006). Expert leaders, such as the heads of departments, must certainly have expertise in other non-scientific areas too, which they might already have proven on their way to the top positions of a university (Goodall, 2009). Thus, if good scientific performance is only the foundation, which characteristics, talents or expertise are necessary beyond that? As mentioned in the literature review, entrepreneurial universities have to translate knowledge into economic activities (Etzkowitz, 2016), they have to deliver on their third missions (Jones et al., 2013), foster relationships with industry and they have to integrate managerial and market-related practices and tools (Tijssen, 2006). Leaders play a crucial role in this transition as they are responsible for the implementation of changes (Peus et al., 2015) and serve as entrepreneurial role models, and they must be able to identify business opportunities (Kirby et al., 2011).

Hence, we assumed that it is the IE and ILE of the heads of departments and hypothesized that those experiences should impact scientific and entrepreneurial key aspects such as the departments' potential to acquire third-party funds or the departments' patent output. With regard to the impact on third-party funding, our investigation revealed a low positive effect for IE. However, ILE had no effect and we further found no support that the publication performance of the heads of departments jointly interacts with the IE and ILE to be positively associated with the level of thirdparty funding. This leaves us with the question, does ILE generally not pay off in an academic environment? In this regard, we found evidence that ILE affects the patent output of departments. Presumably, heads of departments with ILE are more likely to take a possible route of commercializing research results. Therefore, our results suggest that entrepreneurial universities can profit from a head of department with IE in those activities, which Etzkowitz (2016) summarizes as the initial phase of entrepreneurial universities (e.g. raising additional resources). However, if universities seek to enter in the second phase of Etzkowitz's (2016) classification, i.e. taking an active role in commercializing the IP of its members, the ILE of heads gains in importance.

Hence, for the interpretation of our results we have to differentiate between academic engagement and commercialization. Perkmann et al. (2013) describe academic engagement as a way to transfer academic knowledge to industry through collaborative research, contract research, consulting or informal activities, while they see the focus of commercialization as being primarily on gaining financial rewards. Contrary to patents, licensing or other entrepreneurial activities, the acquisition of third-party funding is not about reaping money. It is about accessing resources to support the scientists' research agenda (Perkmann et al., 2013); a way to finance the own research, to maintain the required infrastructure or to employ research assistants. Patents, on the other hand, are aimed predominantly at making profit from research results. The protection of IP is a key element of entrepreneurial universities (Etzkowitz, 2016) and researchers must evaluate what ideas may be commercially valuable and seize opportunities to develop inventions that can be patented (Perkmann et al., 2013). Apparently, heads of departments with former ILE are more acquainted with this challenge or they are more likely to see and take the chance to apply for a patent and commercialize the own scientific research. Thus, our results are in line with Kirby et al. (2011), who postulate that nowadays university leaders must be capable of identifying business opportunities, and with Balconi and Laboranti (2006) who claim that researchers in applied fields must be intimately familiar with industry and industrial technology. Therefore, our results support the assumption that it is particularly advantageous for the commercialization of academic knowledge to have had ILE in the past. 


\subsection{Characteristics of departments}

There are some further results, which we want to discuss critically in the following paragraphs. Regarding the characteristics of university departments, our results reveal some interesting relationships, which need further research. First, we found support for an inverse u-shaped relationship between external funding and the publication performance specifically for the public third-party funds. These findings are also in line with the studies of Bonaccorsi et al. (2006) and Schmoch and Schubert (2009). Bonaccorsi et al. (2006) found that in the first place productivity improves through collaboration with industry, but beyond a certain level the engagement in such collaborations may be too demanding and subsequently deteriorates the publication profile. They argue that universities initially benefit from more resources provided by industry. However, according to the authors, their preliminary results also suggest that at least for some institutions a trade-off applies when being exposed to industry requests, which eventually may reduce publication productivity. Similarly, Schmoch and Schubert (2009) reported that the acquisition of third-party funds may affect research efficiency negatively, especially if the level of third-party funds is already very high. The authors furthermore assume that different third-party types cause different effects. A result that is likewise supported by our findings, as private and public third-party funds revealed different effects. Second, the size of a department has an effect, but the question remains as to whether there is an "optimal" size for departments. Third, the location of a university plays a role but, contrary to other sectors, it must not be a metropolitan area. In fact, many successful universities (and not only the investigated ones) are located in smaller cities. Obviously, other factors are crucial for successful universities and future research might take a closer look at the location of universities and research performance. Finally, we found evidence that the discipline is an important factor in explaining the publication output as well as the third-party funding. Technical sciences and engineering departments and departments in technical universities have, on average, a lower publication output compared to other departments. On the other hand, these departments generate more third-party funds. However, this does not hold for the private funds. In general, technical sciences departments are often more applied in contrast to natural science departments and have closer relationships with industry. Moreover, technical universities generate fewer patents. This might be due to their having specific patent policies, with a more focused orientation toward patenting only in promising fields, which in the end results in a smaller number of patents.

\section{Conclusions and implications}

Today's universities are confronted with increasing demands from industry and society (Pritchard et al., 2016). To meet these new requirements, universities have to reconsider their research and teaching focus, to adapt their funding sources and to adjust their internal rules and organization (Rybnicek and Königsgruber, 2019; Kailer, 2009; Elia et al., 2017). These changes also influence the necessary competencies and characteristics of academic leaders. Our study contributes to the literature by investigating whether prior IE or ILE of the heads of departments might influence the departments' publication output, the ability to acquire external research funds or their entrepreneurial activities (e.g. the commercialization of research results through patents). Our research has several implications.

\subsection{Theoretical implications}

The paper at hand provides a more comprehensive model, explaining the performance of university departments. We found evidence that different experiences of the head stimulate the productivity of the department regarding its scientific and entrepreneurial activities. Depending on the actual focus of the university, this may influence the recruitment process and the necessary job qualifications of heads in the near future (see also the practical implications). 
$\mathrm{MD}$

57,12

Most importantly in this context, our results suggest that new rankings are required to measure and compare universities and their scientists. If - and this is not set in stone - universities are to be more entrepreneurial and focus increasingly on their third mission, the other two missions (research and teaching) will have to be reduced in their importance. Eventually, the scientific capability of heads in particular, or scientists and professors in general, will become less important compared to today. This has multiple theoretical implications regarding the measurement of academic performance. Therefore, our results support Etzkowitz's (2016) demand that the dominant metrics to determine university rankings and performance need revision. New measuring parameters have to be included while simultaneously balancing with the existing ones. However, our results regarding the inverse u-shaped relationship between external funding and publication performance also indicate how challenging this task might be. An increasing number of researchers, like Schmoch and Schubert (2009), advocate that thirdparty funds do not work well as performance indicators and therefore should be used only with great care. Although our findings support this conclusion, more research is needed to understand the relationship between the acquisition of third-party funds and other performance indicators in research and teaching.

\subsection{Practical implications}

Based on our research, we also derived several practical implications. First, in line with Goodall (2009) our results suggest that the scientific ability of researchers should be key when selecting heads of departments due to the fact that scientific performance is still a key factor that characterizes those organizations. However, when universities seek to focus on other, for example, entrepreneurial activities, then other competencies come into play. Importantly, recent concepts and ideas like the entrepreneurial university (Etzkowitz, 2003), the third mission of universities (Zomer and Benneworth, 2011), or the Triple-Helix (Etzkowitz and Leydesdorff, 2000) indicate that the actual focus of universities is currently subject to change. Similar to the changes in other sectors, the adoption of business logic will influence the universities' habits of working, their modes of organizing activities and their orientation (Poutanen and Kovalainen, 2016). If these developments continue, the cards are likely to be reshuffled and former IE and ILE will become more important. We therefore believe, that the heads of departments will play a decisive role in the transition toward becoming an entrepreneurial university, and universities are well advised to integrate these qualifications and experiences in the job specifications of heads, professors or scientists in general.

Second, the entrepreneurial university requires scientists that can handle the demands of both universities and economy. In that regard, Etzkowitz and Viale (2010) refer to scientists with double and even triple lives in university, industry and government. Scientists with experiences outside the university will be capable of adapting quickly to changes introduced by the entrepreneurial university. The traditional "truth-seeking scientist" evolves toward the "entrepreneurial scientist," linking virtuously knowledge and innovation (Etzkowitz and Viale, 2010; Elia et al., 2017). Our results suggest that heads of departments with ILE are better equipped to commercialize research findings and face the demands of the market. Hence, universities should create environments and processes that allow such double lives for example, through part-time jobs (or even part-time professorships) or by facilitating the change from an industrial to a university job.

Third, the ambition to collaborate with industry and other non-scientific partners is both an opportunity and a risk for researchers. It certainly offers new possibilities and additional resources to enhance research productivity, but in some cases the requirements and expectations of industry partners might also become too demanding, which eventually impedes pure research (Bonaccorsi et al., 2006). As a matter of fact, in many scientific disciplines the researchers' careers are still dependent on their ability to be published. 
Therefore, when excessive third-party projects negatively influence the publication performance of researchers, in the long run this can have severe consequences, especially for junior scientists (Conraths and Smidt, 2005). This is supported by our results. We found that the IE of heads of departments positively impacts the departments' third-party acquisition. However, after a given third-party level, the departments' publication output can diminish. Hence, to protect the own scientific staff members it seems an important leadership task of those heads not to overdo the own ambitions regarding third-party projects. With this in mind, there are good reasons to be careful when implementing the acquisition of third-party funds as performance indicator (Schmoch and Schubert, 2009), and this applies to individual researchers (e.g. as criterion in tenure track positions) as well as entire departments (e.g. in performance agreements).

Lastly, our results support the idea of encouraging scientists to acquire leadership skills and leadership experiences. Recent research suggests that the motivation to lead significantly influences how well a leader performs (Bergner et al., 2019). This motivation is influenced by the individual's interests and previously gained leadership experience (Bergner et al., 2019). However, way too often scientists end up in leadership roles without even seeking them (Rowley and Sherman, 2003). Our results show that the performance of the whole department might be influenced by the leadership experiences of its head. Therefore, policymakers should strive to support scientists to be more motivated in their roles as leaders and to gain leadership experience.

\subsection{Limitations and final remarks}

When interpreting the results of this study one has to bear in mind the limitations. We have measured the publication output of the institutes but have not measured the impact of research, as for instance by citations. We focused our research on natural sciences, technical sciences and engineering and the results can thus not be generalized to other disciplines. Moreover, we have excluded heads of departments who did not consistently carry out their position from 2013 to 2015 , though this could have had an influence on our results. We have not dealt with dynamic effects. Such effects could occur, for instance, as more efficient researchers might more successfully acquire external funds, which further strengthen their capacity to publish and attract additional third-party funds. We have not considered experiences in the public sector or in non-profit organizations, as we assume that entrepreneurial universities increasingly align with requirements, tools and skills more commonly associated with the private sector. However, future studies might investigate whether there are also significant effects for other sectors. We investigated the relationship between third-party funding and publication output over a three-year period. As many departments are of a considerable size, with a number of researchers publishing and acquiring research funds simultaneously, we assume that the results are robust over time. In this context, we also ran some models with a time lag between the explanatory and dependent variable, which revealed no diverging results. However, time-lagged models might be used in future research to better deal with the reverse causality problem. We have used two categories for third-party funding, i.e. public and private funds, which capture heterogeneous funding sources. Studying different categories of funding streams in more detail might be worthwhile in a further study. Another potential limitation refers to our measurement of ILE as the number of years in supervisory positions, as experience alone does not necessarily improve the effectiveness of leaders (Bass and Bass, 2008; Fiedler, 1970). Furthermore, we are not able to draw any conclusions about the career choice of the heads of departments and possible motives for their change from industry to university. Moreover, we measured only the number of patents as one form of commercializing scientific findings; however, it might also be of interest to investigate the impact of spin-off companies. 


\section{Note}

1. University of Vienna, University of Graz, University of Innsbruck, University of Salzburg, Vienna University of Technology, Graz University of Technology, Montan University of Leoben, University of Natural Resources and Life Sciences of Vienna, University of Linz, University of Klagenfurt.

\section{References}

American Psychological Association (2013), Publication Manual of the American Psychological Association, 6th ed., American Psychological Association, Washington, DC.

Balconi, M. and Laboranti, A. (2006), "University-industry interactions in applied research. The case of microelectronics”, Research Policy, Vol. 35 No. 10, pp. 1616-1630.

Banal-Estañol, A., Jofre-Bonet, M. and Lawson, C. (2015), "The double-edged sword of industry collaboration. Evidence from engineering academics in the UK", Research Policy, Vol. 44 No. 6, pp. 1160-1175.

Bass, B.M. and Avolio, B.J. (Eds) (1994), Improving Organizational Effectiveness Through Transformational Leadership, Sage Publications, Thousand Oaks, CA.

Bass, B.M. and Bass, R.-E. (2008), The Bass Handbook of Leadership: Theory, Research, and Managerial Applications, 4h ed., Free Press, New York, NY.

Bergner, S. (2015), "Personale Führung an Universitäten", in Gutschelhofer, A., Rybnicek, R. and Raggautz, A. (Eds), Universitäre Steuerung: Konzepte, Anwendungen und Trends für ein qualitatives Hochschulmanagement, Styrian Spirit of Management and Entrepreneurship, Neue Ausg, Leykam, Graz, pp. 221-233.

Bergner, S., Kanape, A. and Rybnicek, R. (2019), "Taking an interest in taking the lead: the influence of vocational interests, leadership experience and success on the motivation to lead", Applied Psychology, Vol. 68 No. 1, pp. 202-219.

BMWFW (2014), "Universitätsbericht 2014”, available at: www.bmdw.gv.at/Presse/ AktuellePresseMeldungen/Documents/Universit\%C3\%A4tsbericht_2014.pdf (accessed April 11, 2019).

BMWFW (2016), “Österreichischer Forschungs- und Technologiebericht 2016”, available at: www.bmvit.gv.at/innovation/publikationen/technologieberichte/downloads/ftbericht2016_ printversion.pdf (accessed April 11, 2019).

Bolli, T. and Somogyi, F. (2011), "Do competitively acquired funds induce universities to increase productivity?”, Research Policy, Vol. 40 No. 1, pp. 136-147.

Bonaccorsi, A., Daraio, C. and Simar, L. (2006), "Advanced indicators of productivity of universities. An application of robust nonparametric methods to Italian data”, Scientometrics, Vol. 66 No. 2, pp. 389-410.

Carayol, N. and Matt, M. (2006), 'Individual and collective determinants of academic scientists' productivity", Information Economics and Policy, Vol. 18 No. 1, pp. 55-72.

Conraths, B. and Smidt, H. (2005), "The funding of university-based research and innovation in Europe. An explanatory study", available at: https:/immagic.com/eLibrary/ARCHIVES/GENERAL/ EUA_EU/E050418C.pdf (accessed April 11, 2019).

Costa, P.T. and McCrae, R.R. (1992), Revised Neo Personality Inventory (neo-pi-r) and Neo Five-Factor Inventory (neo-ffi), Psychological Assessment Resources, Odessa, FL.

Dietz, J.S. and Bozeman, B. (2005), "Academic careers, patents, and productivity. Industry experience as scientific and technical human capital", Research Policy, Vol. 34 No. 3, pp. 349-367.

Elia, G., Secundo, G. and Passiante, G. (2017), "Pathways towards the entrepreneurial university for creating entrepreneurial engineers. An Italian case", International Journal of Entrepreneurship and Innovation Management, Vol. 21 Nos 1/2, pp. 27-48.

Etzkowitz, H. (2003), "Research groups as 'quasi-firms'. The invention of the entrepreneurial university", Research Policy, Vol. 1 No. 32, pp. 109-121. 
Etzkowitz, H. (2016), "The entrepreneurial university. Vision and metrics", Industry and Higher Education, Vol. 30 No. 2, pp. 83-97.

Etzkowitz, H. and Leydesdorff, L. (2000), "The dynamics of innovation. From National Systems and "Mode 2" to a Triple Helix of university-industry-government relations", Research Policy, Vol. 2 No. 29, pp. 109-123.

Etzkowitz, H. and Viale, R. (2010), "Polyvalent knowledge and the entrepreneurial university. A third academic revolution?”, Critical Sociology, Vol. 36 No. 4, pp. 595-609.

Fiedler, F.E. (1970), "Leadership experience and leader performance. Another hypothesis shot to hell", Organizational Behavior and Human Performance, Vol. 5 No. 1, pp. 1-14.

Gibbons, M., Limoges, C., Nowotny, H., Schwartzman, S., Scott, P. and Trow, M. (2002), The New Production of Knowledge: The Dynamincs of Science and Research in Contemporary Science, 7th ed., Sage Publications, London.

Godin, B. and Gingras, Y. (2000), "The place of universities in the system of knowledge production", Research Policy, Vol. 29 No. 2, pp. 273-278.

Goodall, A.H. (2006), "Should top universities be led by top researchers and are they?", Journal of Documentation, Vol. 62 No. 3, pp. 388-411.

Goodall, A.H. (2009), "Highly cited leaders and the performance of research universities", Research Policy, Vol. 38 No. 7, pp. 1079-1092.

Goodall, A.H., McDowell, J.M. and Singell, L.D. Jr (2014), "Leadership and the research productivity of university departments", available at: https://ssrn.com/abstract=2385160 (accessed December 6, 2017).

Gosling, J., Bolden, R. and Petrov, G. (2009), "Distributed leadership in higher education. What does it accomplish?”, Leadership, Vol. 5 No. 3, pp. 299-310.

Gulbrandsen, M. and Smeby, J.-C. (2005), "Industry funding and university professors' research performance", Research Policy, Vol. 34 No. 6, pp. 932-950.

Harvey, J., Pettigrew, A. and Ferlie, E. (2002), "The determinantes of research group performance. Towards Mode 2?", Journal of Management Studies, Vol. 39 No. 6, pp. 22-2380.

Hottenrott, H. and Thorwarth, S. (2011), "Industry funding of university research and scientific productivity”, Kyklos, Vol. 64 No. 4, pp. 534-555.

Jones, O., Macpherson, A. and Jayawarna, D. (2013), Resourcing the Start-Up Business: Creating Dynamic Entrepreneurial Learning Capabilities, Taylor and Francis, New York, NY.

Judge, T.A., Bono, J.E., Ilies, R. and Gerhardt, M.W. (2002), "Personality and leadership. A qualitative and quantitative review”, Journal of Applied Psychology, Vol. 87 No. 4, pp. 765-780.

Kailer, N. (2009), "Entrepreneurship education. Empirical findings and proposals for the design of entrepreneurship education concepts at universities in German-speaking countries", Journal of Enterprising Culture, Vol. 17 No. 2, pp. 201-231.

Kirby, D.A., Guerrero, M. and Urbano, D. (2011), "Making universities more entrepreneurial. Development of a model", Canadian Journal of Administrative Sciences / Revue Canadienne des Sciences de l'Administration, Vol. 28 No. 3, pp. 302-316.

Laredo, P. (2007), "Revisiting the third mission of universities. Toward a renewed categorization of university activities?”, Higher Education Policy, Vol. 20 No. 4, pp. 441-456.

Leisytë, L. and Kizniene, D. (2006), "New public management in Lithuania's higher education”, Higher Education Policy, Vol. 19 No. 3, pp. 377-396.

Lombardi, R., Massaro, M., Dumay, J. and Nappo, F. (2019), "Entrepreneurial universities and strategy: the case of the University of Bari", Management Decision, Advance Online Publication.

McCormack, J., Propper, C. and Smith, S. (2014), "Herding cats? Management and university performance", The Economic Journal, Vol. 124 No. 578, pp. F534-F564.

Massy, W.F. and Wilger, A.K. (1995), "Improving productivity. What faculty think about it - and it's effect on quality", Change: The Magazine of Higher Learning, Vol. 27 No. 4, pp. 10-20.

Industry and leadership experiences 
$\mathrm{MD}$

57,12

Mintzberg, H. (1980), "Structure in 5's. A synthesis of the research on organization design", Management Science, Vol. 26 No. 3, pp. 322-341.

Packham, G., Jones, P., Miller, C., Pickernell, D. and Thomas, B. (2010), “Attitudes towards entrepreneurship education. A comparative analysis", Education + Training, Vol. 52 Nos 8/9, pp. 568-586.

Perkmann, M., Tartari, V., McKelvey, M., Autio, E., Broström, A., D’Este, P., Fini, R., Geuna, A., Grimaldi, R., Hughes, A., Krabel, S., Kitson, M., Llerena, P., Lissoni, F., Salter, A. and Sobrero, M. (2013), "Academic engagement and commercialization: a review of the literature on universityindustry relations”, Research Policy, Vol. 42 No. 2, pp. 423-442.

Peus, C., Welpe, I., Weisweiler, S. and Frey, D. (2015), "Führung an Hochschulen", in Felfe, J. (Ed.), Trends der psychologischen Führungsforschung: Neue Konzepte, Methoden und Erkenntnisse, Psychologie für das Personalmanagement, Hogrefe, Göttingen, pp. 527-539.

Pinheiro, R., Langa, P.V. and Pausits, A. (2015), "One and two equals three? The third mission of higher education institutions", European Journal of Higher Education, Vol. 5 No. 3, pp. 233-249.

Polster, C. (2007), "The nature and implications of the growing importance of research grants to Canadian universities and academics", Higher Education, Vol. 53 No. 5, pp. 599-622.

Poutanen, S. and Kovalainen, A. (2016), "Professionalism and entrepreneurialism", in Dent, M., Bourgeault, I.L., Denis, J.-L. and Kuhlmann, E. (Eds) The Routledge Companion to the Professions and Professionalism, Routledge Companions in Business, Management and Accounting, Taylor and Francis, London, pp. 116-128.

Pritchard, R.M.O., Pausits, A. and Williams, J. (Eds) (2016), Positioning Higher Education Institutions: From Here to There, Sense Publishers, Dordrecht.

Röpke, J. (1998), “The entrepreneurial university: innovation, academic knowledge creation and regional development in a globalized economy", working paper, Philipps-Universität Marburg.

Rosenstiel, L.V. (2006), "Leadership and change", in Bruch, H., Krummaker, S. and Vogel, B. (Eds), Leadership: Best Practices and Trends, 1. Aufl., Gabler Verlag, Wiesbaden, pp. 145-156.

Rouse, W.B., Cannon-Bowers, J.A. and Salas, E. (1992), "The role of mental models in team performance in complex systems", IEEE Transactions on Systems, Man, and Cybernetics, Vol. 22 No. 6, pp. $1296-1308$.

Rowley, D.J. and Sherman, H. (2003), “The special challenges of academic leadership”, Management Decision, Vol. 41 No. 10, pp. 1058-1063.

Rybnicek, R. (2015), “Akzeptanz einer modernen Universität”, in Gutschelhofer, A., Rybnicek, R. and Raggautz, A. (Eds), Universitäre Steuerung: Konzepte, Anwendungen und Trends für ein qualitatives Hochschulmanagement, Styrian Spirit of Management and Entrepreneurship, Neue Ausg, Leykam, Graz, pp. 235-246.

Rybnicek, R. and Königsgruber, R. (2019), "What makes industry-university collaboration succeed? A systematic review of the literature", Journal of Business Economics, Vol. 89 No. 2, pp. 221-250.

Rybnicek, R., Bergner, S. and Suk, K. (2016), "Führung in expertenorganisationen", in Felfe, J. and van Dick, R. (Eds), Handbuch Mitarbeiterführung, Springer, Berlin and Heidelberg, pp. 227-237.

Schmoch, U. and Schubert, T. (2009), "Sustainability of incentives for excellent research - the German case", Scientometrics, Vol. 81 No. 1, pp. 195-218.

Secundo, G., Schiuma, G. and Passiante, G. (2017), "Entrepreneurial learning dynamics in knowledgeintensive enterprises", International Journal of Entrepreneurial Behavior \& Research, Vol. 23 No. 3, pp. 366-380.

Simon, H.A. (1976), Administrative Behavior: A Study of Decision-Making Processes in Administrative Organization, 3rded. with New Introd, Free Press, New York, NY.

Slaughter, S. and Leslie, L.L. (2001), "Expanding and elaborating the concept of academic capitalism", Organization, Vol. 8 No. 2, pp. 154-161.

Sporn, B. (2001), "Building adaptive universities. Emerging organisational forms based on experiences of European and US universities", Tertiary Education and Management, Vol. 7 No. 2, pp. 121-134. 
Statistics Austria (2013), Österreichische Systematik der Wissenschaftszweige 2012, Statistics Austria, Vienna.

Tabachnick, B.G. and Fidell, L.S. (2014), Using Multivariate Statistics, Pearson Custom Library, 6th ed. Pearson New International Edition, Pearson Education, Harlow.

Industry and leadership experiences

Teodorescu, D. (2000), “Correlates of faculty publication productivity. A cross-national analysis", Higher Education, Vol. 2 No. 39, pp. 201-222.

Tijssen, R.J.W. (2006), "Universities and industrially relevant science. Towards measurement models and indicators of entrepreneurial orientation", Research Policy, Vol. 35 No. 10, pp. 1569-1585.

van Looy, B., Ranga, M., Callaert, J., Debackere, K. and Zimmermann, E. (2004), “Combining entrepreneurial and scientific performance in academia. Towards a compounded and reciprocal Matthew-effect?", Research Policy, Vol. 33 No. 3, pp. 425-441.

van Vught, F. (1999), "Innovative universities", Tertiary Education and Management, Vol. 5 No. 4, pp. 347-354.

Verbree, M., Horling, E., Groenewegen, P., Van der Weijden, I. and Besselar, P. (2011), “Addressing leadership and management of research groups. A multivariate study", Rathenau Institute Working paper No. 1104, Den Haag.

Vroom, V.H. and Yetton, P.W. (1973), Leadership and Decision-Making, University of Pittsburgh Press, Pittsburgh, PA.

Weckowska, D.M., Molas-Gallart, J., Tang, P., Twigg, D., Castro-Martínez, E., Kijeńska-Dąbrowska, I., Libaers, D., Debackere, K. and Meyer, M. (2018), "University patenting and technology commercialization. Legal frameworks and the importance of local practice", R\&D Management, Vol. 48 No. 1, pp. 88-108.

Ziman, J. (1995), "Prometheus Bound. Science in a dynamic steady state", in Johnston, R. (Ed.), Prometheus Bound: Science in a Dynamic Steady State by John Ziman, Cambridge University Press, Cambridge, ix+289.

Zomer, A. and Benneworth, P. (2011), "The rise of the university's third mission", in Enders, J., Boer, H.F. and Westerheijden, D.F. (Eds), Reform of Higher Education in Europe, Sense Publishers, Rotterdam, pp. 81-103.

\section{Corresponding author}

Robert Rybnicek can be contacted at: robert.rybnicek@uni-graz.at

(The Appendix follows overleaf.) 
Appendix 1

57,12

3344

\begin{tabular}{lccccll}
\hline Independent & Mean & SD & Min. & Max. & Source & Description \\
\hline $\begin{array}{l}\text { Publication output } \\
\text { of the head }\end{array}$ & 0.25 & 0.44 & 0 & 1 & $\begin{array}{l}\text { Research } \\
\text { portal }\end{array}$ & $\begin{array}{l}\text { Publications, monographs, edited books and } \\
\text { proceedings }\end{array}$
\end{tabular}

of the head of

department

$\begin{array}{lllll}\text { Publication output } 66.02 & 64.41 & 0.33 & 378.33 & \text { Research }\end{array}$

of the department

Patents

Third-party

funding total

Third-party

funding public

Third-party

funding private

Size

$\begin{array}{lllll}1.32 & 3.91 & 0 & 34 & \text { Rortal } \\ & & & & \end{array}$

portal

$\begin{array}{lllll}30.47 & 13.06 & 0.00 & 67.26 & \text { Statistics }\end{array}$

Austria

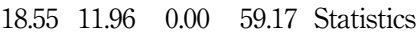

Austria

$\begin{array}{lllll}8.21 & 9.87 & 0.00 & 42.87 & \text { Statistics }\end{array}$ Austria

$\begin{array}{llll}16.33 & 15.40 & 1.01 & 101.35 \text { Statistics }\end{array}$

Austria

Technical sciences

$\begin{array}{lllll}0.52 & 0.50 & 0 & 1 & \text { Statistics }\end{array}$

Vienna

$\begin{array}{lllll}0.37 & 0.47 & 0 & 1 & \end{array}$

Austria

Technical

university

$\begin{array}{lrrrrr}\text { Age } & 55.05 & 7.20 & 38 & 75 & \mathrm{CV} \\ \text { IE } & 0.40 & 0.50 & 0 & 1 & \mathrm{CV}\end{array}$

ILE

$0.24 \quad 0.43 \quad 0$

ILE in months
Table AI.

List of variables proceedings

Publications, monographs, edited books and proceedings

Number of patents

Data from 2013 to 2015

Data from 2013 to 2015

Data from 2013 to 2015

Data from 2013 to 2015

$52 \%$ (108) of the departments belong to technical sciences and engineering 3 out of the 10 universities are located in Vienna, 77 departments (37\%) are part of the 3 universities in Vienna

3 universities among the 10 universities are technical universities; 125 departments $(60 \%)$ belong to one of the technical universities Category personal data or data from the commercial register

Including industry/private sector experience on the CVs (after master/diploma degree) and supervisory board function according to the commercial register and Excluding university jobs, non-governmental organizations or other public positions

1 Number of functions within a company or in $\begin{array}{ll}\text { Commercial } & \text { Number } \\ \text { register } & \text { diverse companies (owner, manager or }\end{array}$ $\begin{array}{lllll}26.6159 .95 & 0.00 & 277.00 & \text { Commercial } & \text { authorized representatives of companies) } \\ \text { Calculated from functions (owner, manager }\end{array}$ register or authorized representatives of companies) until July 31, 2017 in case of active functions 
Appendix 2

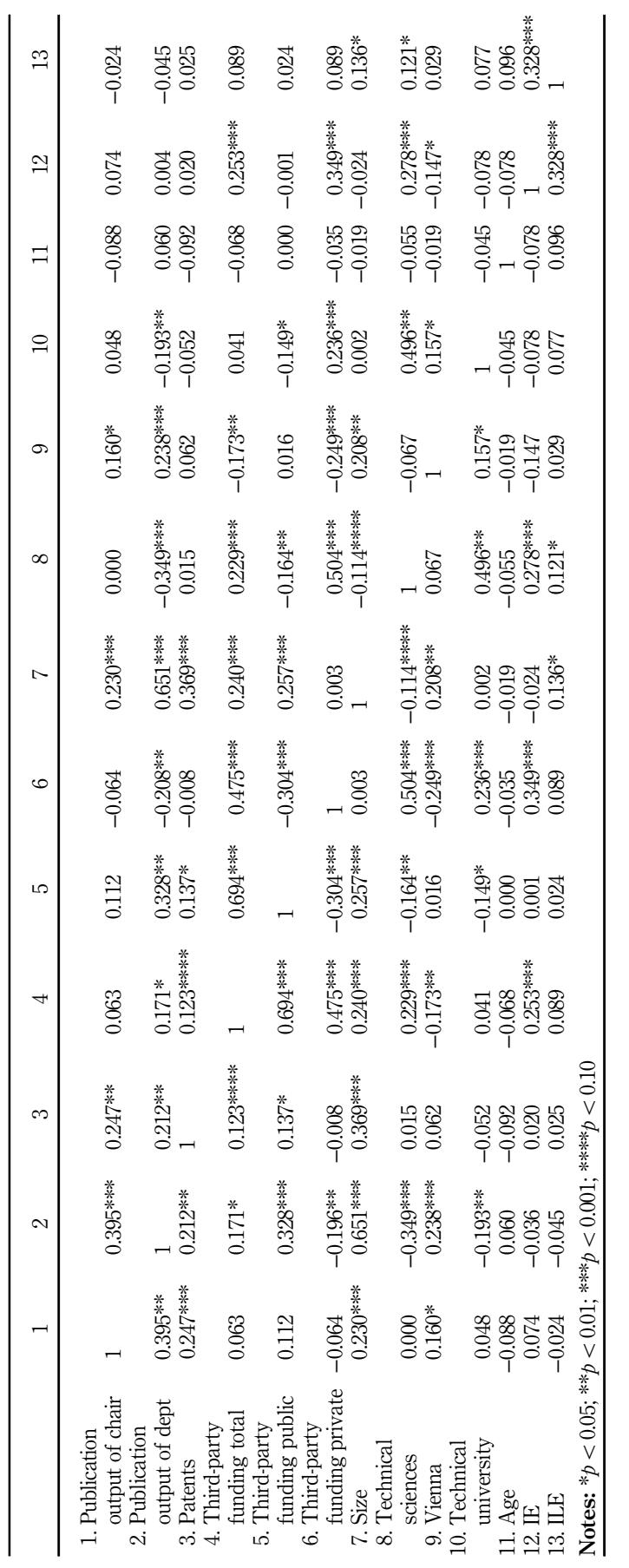

Industry and leadership experiences

3345
Table AII.

Cross-correlation among the variables 